\title{
Chinese Woman's Table Tennis Team Won 2016 M Corbillion Cup Relying on Techinique and Mental Superiority

\author{
Mei-Fang ZHOU ${ }^{1, a}$, Can ZHOU ${ }^{2, b}$, Jun-Qian YU ${ }^{3, c}$, Qi-Han ZHANG ${ }^{4, d}$ \\ and Qi-Lian CHENG ${ }^{5, e, *}$
}

1,2,3,4,5P.E Department of Jiangxi Normal University, Nanchang, Jiangxi, China

a'c,d,562780393@qq.com, ${ }^{b} 371791254 @ q q . c o m,{ }^{e}$ chengqilian@sina.com

${ }^{*}$ Corresponding author

\begin{abstract}
Keywords: World Table Tennis Championships, M Corbillion Cup, perfect technique, mental energy amplification, image and mental rotation, psychological hint
\end{abstract}

\begin{abstract}
Swaythling Cup and M Corbillion Cup of 2016 World Table Tennis Championships was held in Kuala Lumpur, Malaysia. Chinese Woman's Table Tennnis Team won M Corbillion Cup with perfect technique and abundant mental energy. But we cannot be confused by one single technical statistical data and ignore the congnition of image and mental rotation in mental training of table tennis as well as the function and practical significance of mental energy amplification.
\end{abstract}

\section{Introduction}

It's not the number of championship but the quality of the table tennis that makes it become the national game in China. Such quality pushes the development of ping-pong forward. In 2016 World Table Tennis Championships in Kuala Lumpur, Chinese Woman's Table Tennis Team took the crown again with excellent performance against Japanese team. It's the 20th M Corbillion Cup. Japan is a powerful nation of table tennis in the world, which not only enjoys a long history and also has made great contribution to the development of world table tennis. Besides, Japan takes unique place in spin ball and loop play. In particular, it has specialized study on apinning ball and unique technique of the spin. It did work well according to statistics and analysis on the field, having caused a great threat to Chinese Woman's team.

Ishikwa Kasumi, the second Japanese player coming on the stage, played against Li Xiaoxia, the grand slam champion of Chinese Woman's Table Tennis. Ishikwa Kasumi severely threatened Li with skilled and changeable different rotating balls, forcing her to lost in the first two rounds. And the third was nearly close to end with 9:9 but came back finally, which was lucky and also the turning point; of course, it's especially the strength. but also the strength. There is a famous saying for Chinese table tennnis players: fighting won't end until the last minute. That's because everything is possible in the last minute. Even we can change impossibility into possibility with positive mental efforts. The victory of the game depends on perfect technique and mental energy. It's not just a simple conclusion based on untreated or untested winning technical data.

As a result, this projectis trying to obtain the correct conclusion through reading documents and collecting alternately rising scores in actual competitions with method of statistics and analysis so as to effectvely improve combat level of table tennis and the effect of players' mental training. Besides, it will be connacted with cognitive psychology and sport psychology idea to better demonstrate the research conclusion and comprehensive evaluation of this project. 


\section{Demonstration of the Project Research}

\section{Project Analysis and Research Procedure}

\section{Analysis of the Final Combat between Chinese and Japanese Woman's Table Tennis Teams}

Japanese Woman's Table Tennis Team made to the final eight with full victory in group stage in Kuala Lumpur and it made to the top four with 3-0 against Hungary. In the semi-finals, it defeated the North Korea with 3-1. Japanese Women's Table Tennis Team all the way was getting more and more stronger and reached the final on the wave of popularity. It's only one step away from the champion; however, the actual results were moving in the opposite direction beyond their expection. What's the reason? Focusing on the following practical analysis:

In the first match, Chinses player Liu Shiwen played against Ai Fukuhara from Japan. She won the first match with11:5 11:6 11:8 through concise playing of changing the line and angle; and in the second one, Li Xiaoxia played against Ishikawa Kasumi, which was not very smooth. Li lost two rounds with 6:11 and 7:11 due to many mistakes out of slow heat. After which, God of fortune turned eyes to $\mathrm{Li}$ and she came back wih a total reversion, narrowlywinning the Cup by 11:9,11:3 and 11:5. Chinese player fought with Japanese emerging player, the fifteen-year-old teenager Itou Micheng. Even though Ding Ning could go easy wih this Japanese teen, he was not used to play the third match and suffered slow heat in long wait. It's their first meet and Ding was unfamiliar with opponent's playing style. His psychological pressure began to increase. And the Japanese teen started crazy "fight", at this time, Ding Ning lost the first round with 8:11; then he did self-adjustment with squat and cutting serve and pulled the second back with 11:7 and won the third by11:8. He completely controlled the fouth round, giving no chance to Itou Micheng. At last, Ding Ning defeated the Japanese teen with 11:1[1], big score of 3:1. Itou Micheng's psychological imbalance was reponsible for this.

\section{One Edge Ball Witnessed Japanese Woman Players' Psychological Lag}

Sports statistics is a modern science which studies and analyzes the quantitative relation of inevitable factors in happenstance in sports training and competition[2]. In order to explore that Chinese Woman's Table Tennis Team won at "perfect technique + mental energy" against Japanese team in 2016 Kuala Lumpur World Table Tennis Championship, the writer processed the scores in five matches by dispersion and overall analysis to better prove and share the conclusion of this paper in a scientific way.

Japan has made a great contribution to the development of table tennis. And its man or woman's table tennis team have got nomerous achievements, being the champion in history, especially ranking top in recent years. Japan especailly pays attention to the cultivation of cultivation of children and teenagers. The coach of Chinese Woman's Table Tennis team Kong Linghui spoke highly of the 15 -year-old teen Itou Micheng born in 2000. He praised that though Itou is young, but complicated in playing tennis with calm and many unexpected strike [3]; and he was also lavish with his praise for Ishikawa Kasumi who holds rackets with the left hand and is good at playing dead strike, accidentally hitting stability anchor Chinese type; but why Ishikawa Kasumi lost the game against Li Xiaoxia under the promising situation that already leading in the third round and winning the first two? It's not on the technique but the mentation.

In the third round of the final, the sore was 9:9. And Ishikawa Kasumi lost out of an edge ball, which reflected that she didn't make enough mental and ideological preparation. The game is a competition in which anything can happen. In order to help the atghletes play well the key hit at last, Chinese coach Liu Guoliang set the match rule that setting straight victory in five or seven hit in open matches or even tryouts. Keeping fighting to the end, even it's the last hit. An unexpected edge ball often happens, and it is lucky and also fair. Li Xiaoxia corrected an edge ball on time and finally won even the referee has made misjudgment. This is exacly the difference of psychological quality between Chinese team and Japan's. As for Chinese players, they will never give up as long as there is one chance of getting one score. Such confidence is what's lagging behind for Japanese team. 


\section{Statistical Data Certificates the Mental Deficiency of Japanese Woman's Table Tennis Team}

The data is the random outcome of victory or defeat. The occurrence of events without 100 percent is called happanstance. Otherwise, it is an inevitable event. And sport events are mostly accidental events, thus the data must be approved by the statistical processing and will have practical significance in scientific research. In the second match of the final between Japan and Chinese, how would the game develop between Li Xiaoxia and Ishikawa Kasumi? Why did Li Xiaoxia comeback after under the promising situation that Ishikawa Kasumi already leading in the third round and winning the first two? Besed on the comparision and analysis of round 1 and 2 and round 3,4,5, it can be found that the score probability was both over 0.01 in the first and latter three rounds. There is no markable difference [2] (Table 1).

Table 1 The ratio before and after the field of Japanese and Chinese women's team finals in 2016 Kuala Lumpur World Table Tennis Championship [2]

\begin{tabular}{llllll}
\hline & $\begin{array}{l}\text { Round Score } \\
\text { Number }\end{array}$ & $\begin{array}{l}\text { Sum of Score } \\
\text { China/Japan } \\
\text { (3)(4)(5) }\end{array}$ & $\begin{array}{l}\text { Score Rate\% } \\
\text { China/Japan }\end{array}$ & $\begin{array}{l}\text { Rate } \\
\text { China/Japan } \\
\text { Variance }\end{array}$ & $\begin{array}{l}\text { U Test } \\
\text { U/P }\end{array}$ \\
\hline 1 & & $13 / 22$ & $59.10 /-51.52$ & 7.58 & $\begin{array}{l}0.55<\mathrm{U} 2.58 \\
0.55 />0.01\end{array}$ \\
\hline
\end{tabular}

Through the statistical data analysis, the conclusion is: if there's no technical difference, then where lies the difference? The author separately made probabilistic analysis between the "badly hurting and disastrous defeat" round (4) and the winning round (5), the difference is significant, and the ratio reaches $99 \%, \mathrm{P}<0.01$ (Table 2 ).

Table 2 The ratio of round (4) and (5) in 2016 Japanese and Chinese women's team finals in 2016 Kuala Lumpur World Table Tennis Championship

\begin{tabular}{rlllll}
\hline Team & $\begin{array}{l}\text { Round Score } \\
(4 \mathrm{X} 5)\end{array}$ & $\begin{array}{l}\text { Sum of Score } \\
\Sigma \mathrm{X}\end{array}$ & $\begin{array}{l}\text { Score Rate } \\
\%\end{array}$ & $\begin{array}{l}\text { Rate Variance } \\
\%\end{array}$ & $\begin{array}{l}\text { U Test } \\
\text { U/P }\end{array}$ \\
\hline $\begin{array}{l}\text { Chinese } \\
\text { Japanese }\end{array}$ & $11+11 / 3+5$ & $\begin{array}{l}22 / 30 \\
8 / 30\end{array}$ & $73.33 / 26.67$ & 46.66 & $\begin{array}{l}3.29>\mathrm{U} 2.5 \\
8\end{array}$ \\
\hline
\end{tabular}

Ishikawa Kasumi, the dividing crest of the victory is the critical round (3), team competition format is the best of five, Kasumi took the lead by 11:6 11:7. A good start in round (3) for Kasumi resulted in a thought of "victory is within grasp", and dispersed her attention of how to play her strong suit, while at this time Li Xiaoxia has found the method to deal with Kasumi. Thus, in round (3), the score is 9:9, Xiaoxia equalized the scores with a touch lucky ball, and Kasumi was nervous breakdown. All the 15000 audience was shouting encouragement to Chinese team and it became powerless for Kasumi who was completely defeated by Xiaoxia with $26.67 \%$ score rate (Table 2), and the conclusion is: China women's table tennis team is adequate in psychological power to resist the load of mental pressure.

\section{The Idea and Basic Training of Resisting Psychological Pressure}

The special psychological trainings on image, self-confidence and determination of Chinese athletes are important training course. The image is the information stored in the brain in the form of figures, and complex processes of operation, information processing and exploration of the moving object are working through the brain. The image is formed by stimulation the sensory channel [4], sports mainly rely on the image predominated by visual, auditory and tactile (kinesthetic), according 
to the research of Mckellar, the visual image and auditory image are $97 \%$ and $93 \%$ while tactile image is only accounted for 70\%[4]; therefore it is not difficult to find out that the failure rate of Chinese Li Xiaoxia was 59\% in round (1) and (2), wherein the misjudge was accounted for 31.8\%, which shows that the transferring process from visual to auditory then to tactile, cost nearly $60 \%$ of energy, the transformation can't be done unless the identification process was long lasting.

The extension of the process of image recognition is caused by image abstraction, changeability and operation and it is also influenced by imagery and mental rotation dynamic, according to the mental rotation test of letter $(\mathrm{R})$, no matter it is clockwise and counter clockwise rotation, when the graphics inclined to $180^{\circ}$ or upside down, the reaction time will be the longest (Figure 1)[4].
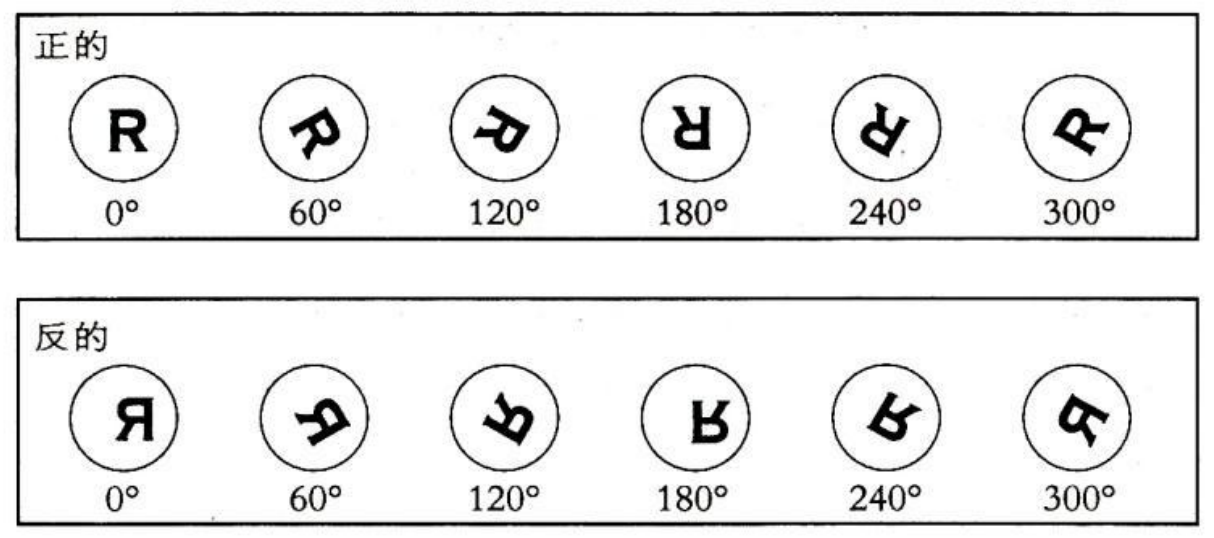

Figure 1: The letter figures of mental rotation test Ps: the numbers in the figures indicate the degree of inclination in a clockwise direction ( Cooper \& Shepard,1973)

According to the experiments, when the figures be in the vertical $\left(0^{\circ}\right.$ to $\left.360^{\circ}\right)$, reaction time will be shortest (figures is in the normal state), only when it is $60^{\circ}$, the reaction time is slightly shorter; the reaction time is the slowest which takes the longest time only when figures is in clockwise (counter clockwise) rotation or in inverted vertical status $\left(180^{\circ}\right)$ (Figure 2) [4].

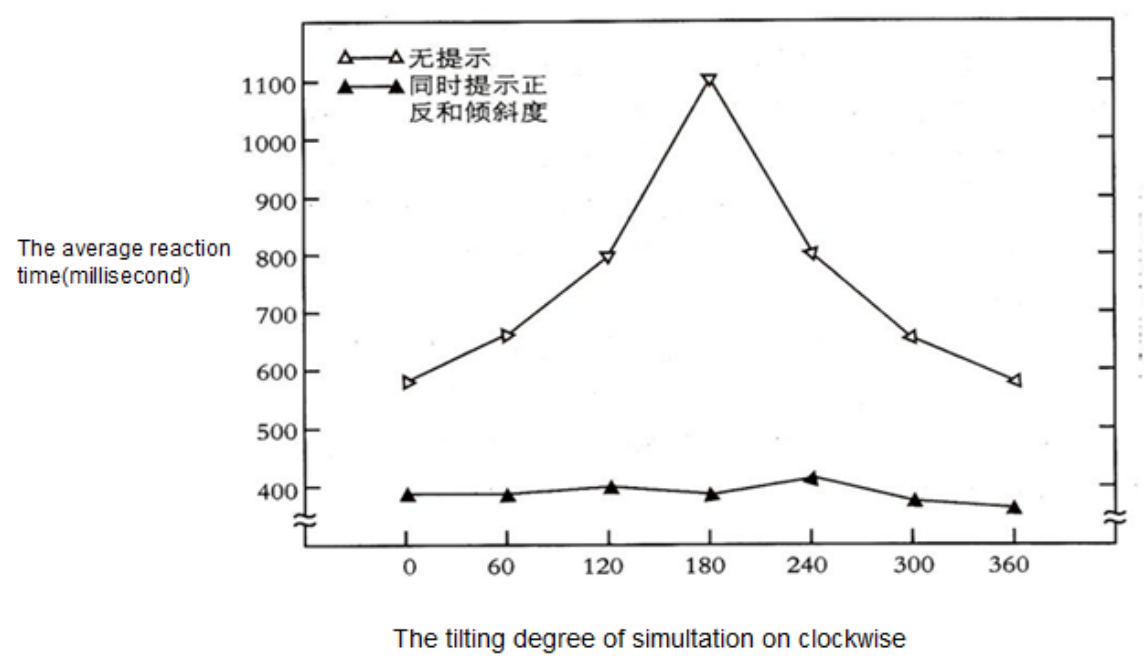

Figure 2: The degree of rotation of the letter figures and the reaction time of the judgement from the testee. Ps: The value of the vertical axis is the average of the "clockwise" and "counter clockwise" two kinds of reaction time. (Cooper \& Shepard,1973)

Of course, some people will doubt that image has the characteristic of simulation, that we can enhance the effects of image technology through the simulation training of table tennis. "Image is 
similar to the things in objective world; it holds some spatial objects of objects [4]. Coach of Chinese women's table tennis Kong Linghui attaches a lot importance to the targeted simulation training. Before the 2016 World Championships, Chinese women's table tennis team was searching for sparring partners who play similarly like Ishikawa Kasumi and Itou Micheng among national professional teams. However, the image and the reality is difficult to be completely similar, especially the skills, movements and styles, even with the precise processing of real, it is impossible to play with the similarly same person with the same skills, therefore, Kong Linghui made the second hard preparation, with round (1) or round (2), transferring from the simulation game to find the unique style adaptability on the scene; but the establishment of patience and confidence to search for the opportunity and to win must be made. Kong Linghui often asks the team members to constantly asking Xiaoxia for "prompts" and enlightening it is necessary to observe the changing technical features of the opponents when play table tennis then use your own strong point to restrict the other and win; even though you lost the round (1), you ought to be patient to find means to win, not to feel like it is the end of the world when you lose round (1) or (2). Be sure to win with confidence and be overturned, this is the winning mentality of Chinese women's table tennis match.

\section{Precise Conclusion}

In 2016, Malaysia Kuala Lumpur World Team Table Tennis Championships, Chinese and Japanese men and women's team, both were promoted into the finals, which revealed a brilliant performance for 15000 spectators. This paper highlights the second sector of Chinese and Japanese Female Table Tennis Championships, where Li Xiaoxia and Ishikawa Kasumi had a breathtaking and tempestuous competition, the powerful data demonstrates the "perfect skills with mental energy" is the basic key to win".

The sports competitions are mostly random chance events, thus, in order to make an end conclusion, it must be processed by the statistical data with the theory of mathematical statistics. The key factor to win in sports competition is affected not only by the skills and psychological factors, but also by competition environment, audience and accidental factors [5], this paper is based on the philosophy and the professional concepts of theory in sports psychology, which foreshadows the conclusions of this paper.

\section{References}

[1] Guojian. China Female Table Tennis Team Won the Twentieth Corbillon Cup, sports.sohu.com, 2016.3.6

[2] Wang Zhongliang. Condensed Sports Statistics, Teaching Research Series, Chinese Education Room of Jiangxi Institute of Education, 1984.10

[3] Phoenix Sport. Kong Linghui Comments on the 3 Backbones: Praising the 15-Year-Old Young Player, isports.ifeng.com 2016.2.25

[4] Peng Danling, Zhang Biyin. Cognitive Psychology(A Famous Experimental Study), Zhejiang Education Publishing House,2004.12.P288-242

[5] Group of Teachers in Higher Normal Colleges, Sports Psychology: Psychological Preparation and Psychological Analysis before Competition (Teaching Materials on Probation), Higher Education Press, 1987.4 